\title{
Efficacy of Sleep Special Technique on Young Healthy Yoga Practitioners
}

\author{
${ }^{1}$ Kalyan Maity, ${ }^{2}$ SK Rajesh ${ }^{3} \mathrm{~V}$. Sureshbabu Venkatasamy
}

\section{ABSTRACT}

Background: Sleep is an indicator of health. Sleep determine many aspects of our life like mood, cognitive functions such as attention and working memory, homeostasis, learning, concentration, etc. Sleep is very essential for the academic progress in college students, whereas most of the sleep-related problems are found in college students worldwide.

Aim: This study aimed to evaluate the positive effect of sleep special technique (SST) on sleep quality, stress level and quality of life in young healthy yoga practitioners.

Materials and Methods: A total of 120 healthy male yoga practitioners were screened and $\mathrm{N}=94$ were randomly allocated into two groups, experimental group $\mathrm{N}=47$, and control group $\mathrm{N}=47$. Experimental group practiced 1 month of (SST), and the control group had no exposure to SST.

Variables Measured: Pittsburgh sleep quality index (PSQI), perceived stress scale (PSS), World Health Organization quality of life-BREF (WHOQOL-BREF), and the vedic personality inventory (VPI)

Results: After one month of SST result showed the significant reduction of the global PSQI score $\left(p<0.001^{* * *}\right)$, perceived stress scale $\left(p<0.001^{* * *}\right)$, and considerable improvement in all domains of $Q O L\left(p<0.001^{* * *}\right)$, Sattva guna $\left(p<0.001^{* * *}\right)$ in the experimental group compared to the control group.

Conclusion: A one-month course of SST has a significantly positive effect on overall sleep quality, quality of life and perceived stress. The transition towards sattva guna was evident during the course of SST intervention.

Keywords: College students, Sleep, Yoga, Young adults

How to cite this article: Maity K, Rajesh SK and Venkatasamy VS. Efficacy of Sleep Special Technique on Young Healthy Yoga Practitioners. Indian Sleep Med 2018;13(3):42-47.

Source of support: Nil

Conflict of interest: None

${ }^{1}$ Postgraduate Scholar, ${ }^{2,3}$ Assistant Professor

${ }^{1-3}$ Anvesana Research Laboratories, Swami Vivekananda Yoga Anusandhana Samasthana (S-VYASA Yoga University), Swami Vivekananda Road, Kalluballu Post, Anekal Taluk, Jigani, Bengaluru, Karnataka, India

Corresponding Author: V. Sureshbabu Venkatasamy, Assistant Professor, Anvesana Research Laboratories, Swami Vivekananda Yoga Anusandhana Samasthana (S-VYASA Yoga University), Swami Vivekananda Road, Kalluballu Post, Anekal Taluk, Jigani, Bengaluru, Karnataka, India, Phone : 9482542873 , Email: sureshbabu@svyasa.org

\section{INTRODUCTION}

According to the American Heritage ${ }^{\circledR}$ Medical Dictionary (2007), sleep is defined as "a natural periodic state of rest for the mind and body in which the eyes usually close and consciousness is completely or partially lost so that there is a decrease in bodily movement and responsiveness to external stimuli." Sleep is a state of rest which plays a significant role in healthy well-being. ${ }^{1}$

Most of the adults take 7 hours of sleep during night time. ${ }^{2}$ Adequate hours of sleeping are required for all the levels of wellbeing such as physical, mental, social and emotional levels. ${ }^{3}$ Every individual spends around onethird of his lifetime in the state of sleep. ${ }^{4}$ Sleep is essential for the proper functioning of our nervous system. ${ }^{5}$ During sleep, most of the physiological systems like the immune system skeletal system and muscular systems are in anabolic phase. ${ }^{6}$ Sleep determine many aspects of our life like mood, cognitive functions such as attention and working memory, homeostasis, learning, concentration, etc. ${ }^{7,8}$ Reduction of sleep duration reduce work efficiency and leads to drowsiness, impaired memory, fatigue, physical performance. ${ }^{5,9}$ There are significant relationships found between sleep quality and health risk behaviors such as fatigue, suicidal thoughts, smoking, and alcohol use in college students. ${ }^{10}$

\section{Circadian Rhythm}

The repeated organized episode of wakefulness followed by sleep is called the sleep-wake cycle. For normal healthy adult sleep-weak cycle comprises 16 hours of wakeful state and 8 hours of sleep state, which is operated by homeostasis and circadian rhythm (CR). ${ }^{11}$ Homeostasis is a natural process by which body maintain its normal functioning state of internal processes such as blood pressure, body temperature and acidbase balance. ${ }^{11} \mathrm{CR}$ is a 24 hours cycle of our physical, mental and behavioral change controlled by the master clock located in the suprachiasmatic nuclei of the hypothalamus. ${ }^{12}$ During the sleep-wake cycle, there are many functional organization changes occur in the brain (e.g., regional cerebral blood flow). ${ }^{13}$ Many studies showed that disturbance in circadian rhythm affects our physiological and pathological factors such as difficulty in getting sleep, short sleep duration, daytime sleepiness, anxiety and irritability. ${ }^{14,15}$ 


\section{Stages of Sleep}

Sleep can be categories into two stages called rapid eye movement (REM) sleep and nonrapid eye movement (NREM) sleep. The NREM sleep again classified into three stages NREM 1, NREM 2 and NREM 3. REM sleep again classified into two stages-phasic and tonic. REM and NREM both compiled together and form one sleep cycle, length is $90-120$ minutes, like this many sleep cycle, occurs in every night. The first sleep cycle comprises short REM sleep duration and long NREM 3 sleep duration and after that long REM sleep duration and short NREM 3 sleep duration can be seen during last sleep cycle. ${ }^{16}$

Based on three fundamental measures electroencephalography (EEG), electrooculography (EOG) and electromyography (EMG) we can categories the sleep into different stages. Electrical activity of the brain and voltage fluctuations resulting from ionic current in neurons of the brain can be measured by (EEG). ${ }^{17}$ Eye movements during sleep can be measured by (EOG). ${ }^{18}$ Electrical activity produced in the skeletal muscles can be measured by (EMG). ${ }^{19}$

The college students are very much worried about their time to fulfill their academic demands. Stress is one of the factors to change the sleep patterns in college students. ${ }^{20}$ The students with psychological stress have more prone to get sleep disturbance and frequent daytime dysfunction. ${ }^{21}$ The previous study showed time concerned students suffer from more sleep problems. ${ }^{22}$ The delayed sleep pattern disturbed the endogenous biological rhythms which creates difficulty in falling asleep, getting up in morning, drowsiness and irritability during the daytime in college students. ${ }^{23}$ Different outside pressure influence on the time is taken to fall asleep and duration of sleep in college students that leads to hallucinations. ${ }^{24}$ Sleep quality in college students has closely associated with their academic performance the poor the quality of sleep is the poor the academic performance was, ${ }^{25,26}$ Another side good sleep quality helps to improve the academic performance, overall health and well-being. ${ }^{27}$

Sleep deprivation (SD) includes either total lack of sleep for some duration of time or less than optimum sleep time. The causes of SD include modern lifestyle and working factors. ${ }^{28,29}$ A person cannot subsist with SD for a week. ${ }^{30}$ Around $25 \%$ of adults are not satisfied with their sleep, $10-15 \%$ has insomnia symptoms, $6-10 \%$ come under the diagnostic criteria for insomnia. ${ }^{31}$ It was found that SD for 24 hours reduces cognitive functions of the right hemisphere of the brain relating to motor, rhythm, receptive and expressive speech, memory and complex verbal arithmetic function..$^{32}$ Lack of sleep leads to many cardiac disorders such as coronary heart disease (CHD), hypertension (HTN) and metabolic disorders such as diabetes, metabolic syndrome, obesity, hypothyroidism, and hypertriglyceridemia. ${ }^{33,34}$ SD also leads to the depressive feeling 35,36 and trigger of anxiety. ${ }^{37}$ Chronic sleep deprivation may also lead to sleep fragmentation..$^{38}$ A recent research conducted on laboratory and multiple epidemiological studies have linked shortsleep duration and poor-sleep quality to obesity risk. ${ }^{39} \mathrm{~A}$ close correlation between sleep duration and body mass index (BMI) and concluded that sleep deprivation has a negative impact on hypothalamus functioning affecting hunger and appetite especially. ${ }^{40}$

Yoga is one of the most scientific philosophies of six ancient philosophies, ${ }^{41}$ which talks about not only the physical body, along with we have four more layers of our existence, such as pranic body, mental body, intellectual body and a spiritual body. ${ }^{42}$ Sleep is an important part of our personality. In ancient yoga, texts sleep is defined as the state in which mental content is absent (Patanjali yoga sutra, 10-1).

Regular yoga practice improves the sleep quality. ${ }^{43,44}$ Yoga also improves sleep efficiency, sleep latency, sleep duration, general well-being along with sleep quality. ${ }^{45}$ The yogic relaxation technique such as mind sound resonance technique also helps to improve sleep quality. ${ }^{46}$ The parasympathetic nervous system is responsible for sleep. Yogic relaxation technique stimulates the parasympathetic nervous system and helps to calm down the mind. ${ }^{47}$

\section{MATERIALS AND METHODS}

\section{Subject}

A total of 120 healthy male yoga practitioners were screened and $\mathrm{N}=94$ subjects were selected based on inclusion and exclusion criteria.

\section{Inclusion Criteria}

Healthy male students, who could understand the English language were included in this study in the age group $18-28$ years.

\section{Exclusion Criteria}

Students with the history of systemic, mental illness and history of hospitalization in the past 6 months they were excluded from the study.

\section{Design of the Study}

Two group pre- and post-design was used for the study.

\section{Methodology}

Random allocation was done to divide the subjects into two groups. Experimental group $\mathrm{N}=47$, control group $\mathrm{N}=47$. Experimental group practiced one month of SST, 
every day 30 minutes at night before going to bed and the control group did not undergo any intervention. Before and after one month we recorded the parameters.

\section{ASSESSMENT}

\section{Pittsburgh Sleep Quality Index}

PSQI is an effective instrument to measure the subjective sleep quality and sleep disturbances. The questionnaire contains seven components (subjective sleep quality, sleep latency, sleep duration, sleep efficiency, sleep disturbance, use of sleep medication, daytime dysfunction) and 18 questions to distinguishes between poor and good sleepers. The purpose of designing PSQI was to provide a reliable, valid and standardized tool to measure of sleep quality. PSQI provide an index which is easy to use for subjects, clinicians, and researchers to interpret. PSQI also measures a variety of sleep disturbances briefly and clinically that might affect sleep quality. Each question has a scoring range from 0 to 3 . Each component also has the same scoring range from 0 to 3 . Total score range is from 0 to 21 . A score of five and above five indicated worse sleep quality or significant sleep disturbances. ${ }^{47}$

\section{Perceived Stress Scale}

The PSS is the most widely used psychological instrument for measuring the perception of stress. In PSS total 10 questions ask about feeling and thoughts during last month. The PSS is more closely related to a life-event which is occurring mostly every day. The PSS is also a better predictor of health and health-related outcomes. ${ }^{48}$

\section{World Health Organization Quality of Life-BREF}

The WHOQOL-BREF is a self-rated questionnaire to assess the quality of life from the subject's perspective which gives a clear-cut view of the subject, the health care profession and researcher. WHO standardizes this questionnaire concerning race and creed. The WHOQOL-BREF having total 4 domains and 26 questions. Twenty-four questions provide a broad and comprehensive assessment of the physical health, psychological health, social relationships, and environment. Other two questions measure an individual's overall perception of quality of life and overall perception of their general health status. Domain scores are scaled in a positive direction; higher scores refer to higher quality of life. ${ }^{49}$

\section{The Vedic Personality Inventory}

VPI was developed by Dr David Wolf in 1998. It helps to assess the three types of vedic personality called trigunas.
The ancient Indian scriptures (Vedas) explained about trigunas; hence, the questionnaire is named as vedic personality inventory. Based on different psychometric properties it evaluates characteristic of triguans (Sattva, Rajas and Tamas). There were total 90 criteria shorted into 56 in 1999 after a reliability and validity analysis. Now the questionnaire contains 15 questions related to Sattva, 19 questions related to Rajas, and 22 questions related to Tamas. ${ }^{50}$

\section{Sleep Special Technique}

SST included walking practice, cantering, abdominal breathing, Nadisuddhi pranayama, Ujjayi pranayama, reverse deep relaxation technique followed by $M, U, A$, M-U-A, Om kara chanting and Om japa.

\section{Statistical Analysis}

Basic descriptive statistics (mean \pm standard deviation) were done by using Microsoft Excel (2016). The statistical analysis was done by using $\mathrm{R}$ (3.1.2) software. Test for normality was done by using the Shapiro-Wilk test. For within group, test for statistical significance was done using a paired t-test for normally distributed data, and Wilcoxson signed rank test for non-normal distribution. For between group, test for significance was done using an independent t-test for normally distributed data and Wilcoxson sum rank test for nonnormal distribution. Test results were considered to be significant for $\mathrm{p}<0.05$.

\section{RESULTS}

The result showed that the significant reduction of sleep duration score $\left(p<0.001^{* * *}\right)$. Sleep efficiency score $\left(\mathrm{p}<0.001^{* * *}\right)$. Sleep latency score $\left(\mathrm{p}<0.001^{* * *}\right)$, sleep disturbance $\left(\mathrm{p}<0.001^{* * *}\right)$, daytime dysfunction( $\mathrm{p}$ $\left.<0.001^{* * *}\right)$, subjective sleep quality $\left(\mathrm{p}<0.001^{* * *}\right)$, and global PSQI score in the experimental group after one month of SST. Significant reduction of perceived stress level $\left(p<0.001^{* * *}\right)$ found in the experimental group. All domains of quality of life $\left(\mathrm{p}<0.001^{* * *}\right)$ and Sattva $\left(\mathrm{p}<0.001^{* * *}\right)$ score improved in the experimental group (Table 1).

Between-group analysis showed the significant reduction in all component of PSQI score and perceived stress score $\left(p<0.001^{* * *}\right)$, except for sleep disturbance. Significant improvement in all domains of quality of life $\left(\mathrm{p}<0.001^{* * *}\right)$, and Sattva guna $\left(\mathrm{p}<0.001^{* * *}\right)$ in the experimental group.

\section{DISCUSSION}

The present study was conducted with an aim to see the effect of a 1 month SST on sleep quality, perceived stress, and quality of life in young healthy yoga practitioners. 
Table 1 : Within group and between group

\begin{tabular}{|c|c|c|c|c|c|c|c|c|}
\hline \multirow{2}{*}{$\begin{array}{l}\text { Sl. } \\
\text { no. }\end{array}$} & \multirow[b]{2}{*}{ Variables } & \multicolumn{3}{|c|}{ Experimental group } & \multicolumn{3}{|c|}{ Control Group } & \multirow{2}{*}{$\begin{array}{c}\text { Between } \\
\text { Group } \\
p \text {-value }\end{array}$} \\
\hline & & Pre & Post & $p$-value & Pre & Post & $p$-value & \\
\hline 1. & Sleep duration & $2.00 \pm 0.66$ & $0.85 \pm 0.59$ & $<0.001^{* * *}$ & $1.85 \pm 0.75$ & $1.64 \pm 0.99$ & 0.0349 & $<0.001^{* * *}$ \\
\hline 2. & Sleep efficiency & $82.59 \pm 11.05$ & $95.37 \pm 3.98$ & $<0.001^{* * *}$ & $78.90 \pm 14.08$ & $79.51 \pm 12.64$ & 0.9578 & $<0.001^{* * *}$ \\
\hline 3. & Sleep latency & $1.06 \pm 0.92$ & $0.36 \pm 0.53$ & $<0.001^{* * *}$ & $1.21 \pm 0.88$ & $1.13 \pm 0.88$ & 0.1294 & $<0.001^{* * *}$ \\
\hline 4. & $\begin{array}{l}\text { sleep } \\
\text { Disturbance }\end{array}$ & $1.28 \pm 0.50$ & $0.89 \pm 0.31$ & $<0.001^{* * *}$ & $1.28 \pm 0.50$ & $1.11 \pm 0.43$ & 0.0235 & 0.0939 \\
\hline 5. & $\begin{array}{l}\text { day time } \\
\text { Dysfunction }\end{array}$ & $0.91 \pm 0.90$ & $0.36 \pm 0.53$ & $<0.001^{* * *}$ & $0.94 \pm 0.84$ & $0.87 \pm 0.71$ & 0.3929 & 0.0020 \\
\hline 6. & $\begin{array}{l}\text { Subjective } \\
\text { sleep quality }\end{array}$ & $1.91 \pm 0.86$ & $0.38 \pm 0.49$ & $<0.001^{* * *}$ & $1.74 \pm 0.90$ & $1.43 \pm 0.95$ & 0.0037 & $<0.001^{* * *}$ \\
\hline 7. & Global PSQI & $8.02 \pm 2.51$ & $2.91 \pm 1.38$ & $<0.001^{* * *}$ & $8.60 \pm 3.09$ & $7.70 \pm 2.94$ & $<0.001^{* * *}$ & $<0.001^{* * *}$ \\
\hline 8. & Physical health & $22.26 \pm 3.42$ & $25.77 \pm 2.65$ & $<0.001^{* * *}$ & $22.13 \pm 3.01$ & $22.17 \pm 3.01$ & 0.8596 & $<0.001^{* * *}$ \\
\hline 9. & $\begin{array}{l}\text { Psychological } \\
\text { health }\end{array}$ & $20.43 \pm 3.43$ & $24.26 \pm 1.76$ & $<0.001^{* * *}$ & $19.72 \pm 3.11$ & $19.87 \pm 3.42$ & 0.3501 & $<0.001^{* * *}$ \\
\hline 10. & $\begin{array}{l}\text { Social } \\
\text { relationship }\end{array}$ & $10.57 \pm 2.27$ & $13.23 \pm 1.46$ & $<0.001^{* * *}$ & $9.72 \pm 2.11$ & $9.87 \pm 2.12$ & 0.127 & $<0.001^{* * *}$ \\
\hline 11. & Environment & $27.74 \pm 4.55$ & $35.60 \pm 2.45$ & $<0.001^{* * *}$ & $26.55 \pm 4.42$ & $27.06 \pm 4.93$ & 0.0200 & $<0.001^{* * *}$ \\
\hline 12. & PSS & $17.09 \pm 5.87$ & $8.09 \pm 3.53$ & $<0.001^{* * *}$ & $18.49 \pm 4.64$ & $18.49 \pm 4.73$ & 0.8102 & $<0.001^{* * *}$ \\
\hline 13. & Sattva & $40.89 \pm 9.19$ & $49.20 \pm 8.22$ & $<0.001^{* * *}$ & $38.89 \pm 8.25$ & $37.44 \pm 6.92$ & 0.0556 & $<0.001^{* * *}$ \\
\hline 14. & Rajas & $31.14 \pm 5.15$ & $29.10 \pm 4.70$ & $<0.001^{* * *}$ & $31.23 \pm 3.92$ & $31.72 \pm 3.68$ & 0.4156 & $<0.001^{* * *}$ \\
\hline 15. & Tamas & $27.98 \pm 5.02$ & $21.70 \pm 4.79$ & $<0.001^{* * *}$ & $29.88 \pm 5.08$ & $30.79 \pm 4.33$ & 0.0329 & $<0.001^{* * *}$ \\
\hline
\end{tabular}

After 1 month of SST result showed the significant reduction of the global PSQI score in both the group. But significantly more reduction found in the experimental group $\left(\mathrm{p}<0.001^{* * *}\right)$. Significant improvement in sleep duration $\left(\mathrm{p}<0.001^{* * *}\right)$, sleep efficiency $\left(\mathrm{p}<0.001^{* * *}\right)$, subjective sleep quality $\left(\mathrm{p}<0.001^{* * *}\right)$, and si gnificant reduction in sleep latency $\left(\mathrm{p}<0.001^{* * *}\right)$, day time dysfunction $\left(\mathrm{p}<0.001^{* * *}\right)$ in experimental group compared to control group. Previous study by Patra and Telles, 2009 to see the positive impact of cyclic meditation on subsequent sleep byusing polysomnography, also supports our current result of increase in quality of sleep after cyclic meditation with a significant improvement of sleep quality $\left(\mathrm{p}<0.001^{* * *}\right)$ in cyclic meditation group compared to supine rest group $\left(\mathrm{p}<0.01^{* *}\right) .^{51}$

There was significant reduction found in perceived stress scale in the experimental group $\left(\mathrm{p}<0.001^{* * *}\right)$ along with the significant improvement in sleep quality. So there is a significant correlation between lower stress level and good sleep quality.

There was significant improvement found in all domains of WHOQL-BREF, physical health $\left(\mathrm{p}<0.001^{* * *}\right)$, psychological health $\left(\mathrm{p}<0.001^{* * *}\right)$, social relationship $\left(\mathrm{p}<0.001^{* * *}\right)$, and environmental factors $\left(\mathrm{p}<0.001^{* * *}\right)$ in experimental group compared to control group. There was significant correlation observed between better quality of life and better quality of sleep.

Previous research work by Hegde, Metri, Chwadhary, Babu and Nagendra, 2017 showed significant reduction of PSQI score from $(6.43 \pm 3.66)$ to $(2.86 \pm 1.86)\left(\mathrm{p}<0.001^{* * *}\right)$, significant reduction of perceived stress from $(13.18 \pm 5.19)$ to $(7.68 \pm 3.79)\left(\mathrm{p}<0.001^{* * *}\right)$, and significant improvement in all domain of quality of life from $(73.54 \pm 10.54)$ to $(84.54$ $\pm 8.78)\left(\mathrm{p}<0.001^{* * *}\right)$ after one month of yoga intervention. ${ }^{52}$ The result of this study is very similar to the results of the current study proving that the practice of SST has a positive influence over PSS, PSQI and QOL.

There was a significant improvement of Sattva $\left(\mathrm{p}<0.001^{* * *}\right)$ and significant reduction of Rajas $\left(\mathrm{p}<0.001^{* * *}\right)$ observed in the experimental group compared to the control group. Significant reduction of Tamas observed in the experimental group $\left(\mathrm{p}<0.001^{* * *}\right)$, whereas significant improvement of Tamas observed in the control group $\mathrm{p}=0.03$.

Previous study by Deshpande et al., 2008 showed that Sattva Guna significantly improves from $(4.65 \pm 0.47)$ to $(5.26 \pm 0.55)$ in yoga group ( $\mathrm{p}<001)$ whereas the physical exercise group improvement of Sattva was from $(4.79 \pm 0.44)$ to $(5.14 \pm 0.65)(p=0.002)$ in age group $\leq 24$ and significant improvement in Sattva in yoga group from $(4.91 \pm 0.59)$ to $(5.12 \pm 0.45)(p=0.001)$. whereas the physical exercise group improve sattva from $(5.00 \pm$ $0.59)$ to $(5.09 \pm 0.62)(\mathrm{p}=0.014)$ in age group $>24$. Rajas $(p=0.002)$ significantly reduced in yoga group compare to the physical exercise group Rajas ( $\mathrm{p}=0.015)$ in age group $>24 .{ }^{51}$ This study by Deshpande et al., 2008 shows increase in Sattva guna after eight weeks of yoga intervention which supports the results of the current study that there is a significant increase in Sattva guna after the 1-month intervention of SST. 


\section{CONCLUSION}

The practice of SST improves subjective sleep quality, overall quality of life and reduced perceived stress level. The transition towards Sattva guna was evident higher through SST Practice.

\section{REFERENCES}

1. World Health Organization. Report on the First Ten Years of the World Health Organization (Internet). Vol. 11. 1958. Available from: http://www.who.int/iris/ handle/10665/88769.

2. Ancoli-israel S, Ayalon L, Salzman C. Special Section: Sleep disorders in the elderly Sleep in the Elderly: Normal Variations and Common Sleep Disorders. Harv Rev Psychiatry. 2008;16(5):279-87.

3. Brand S, Kirov Rm et al. Sleep and its importance in adolescence and in common adolescent somatic and psychiatric conditions. Int J Gen Med 2011;4: 425-42.

4. Rechtschaffen A, et al. Current Perspectives on the Function of Sleep. Perspect Biol Med 1998;41(3):359-90.

5. Daltrozzo J, Claude L, Tillmann B, Bastuji H, Perrin F, et al. Working memory is partially preserved during sleep. Zang Y-F, editor. PLoS One 2012 Dec;7(12):e50997.

6. Waterhouse J, Fukuda Y, Morita T. Daily rhythms of the sleep-wake cycle. J Physiol Anthropol. 2012;31(5):1-14.

7. Alhola P, Polo-Kantola P. Sleep deprivation: Impact on cognitive performance. Neuropsychiatr Dis Treat 2007;3(5): 553-67.

8. Smith-Coggins R, Rosekind MR, Hurd S, Buccino KR, et al. Relationship of day versus night sleep to physician performance and mood. Ann Emerg Med 1994 Nov;24(5):928-34.

9. Geiger-Brown J, Rogers VE, Trinkoff AM, Kane RL, Bausell RB, Scharf SM, et al. Sleep, sleepiness, fatigue, and performance of 12-hour-shift nurses. Chronobiol Int. 2012; 29(2):211-9.

10. Vail-smith K, Felts WM, Becker C, et al. Relationship between sleep quality and health risk behaviors in undergraduate college students. Coll Stud J. 2009;43(3):924.

11. Hall EJ. Guyton and Hall textbook of medical physiology. thirthenth. Elsevier Health Sciences; 2015.

12. Saper CB, Scammell TE, Lu J, et al. Hypothalamic regulation of sleep and circadian rhythms. Nature. 2005;437(7063): 1257-63.

13. Braun AR, Balkin TJ, Wesenten NJ, Carson RE, Varga M, Baldwin $\mathrm{P}$, et al. Regional cerebral blood flow throughout the sleep-wake cycle. An H2(15)O PET study. Brain 1997 Jul ;120(Pt 7):1173-97.

14. Taub JM, Berger RJ, et al. Performance and Mood Following Variations in the Length and Timing of Sleep. Psychophysiology. 1973;10(6):559-70.

15. Taub JM, et al. Effects of Ad Lib Extended-Delayed Sleep on Sensorimotor Performance, Memory and Sleepiness in the Young Adult. Psychol Behav. 1980;25(1):77-87.

16. Kandel ER, Schwartz JH, Jessell TM, Siegelbaum SA, Hudspeth AJ, et al. Principles of Neural Science. Fifth Edit. Steven A, Siegelbaum SA, Hudspeth AJ, editors. New York: McGraw-Hill Education/Medical; 2012. 1747 p.

17. Niedermeyer E, Da Silva FL, et al. Electroencephalography: basic principles, clinical applications, and related fields. fifth edition, editor. Lippincott Williams and Wilkins; 2005.
18. Nonoue S, Mashita M, Haraki S, Mikami A, Adachi H, Yatani H, et al. Sleep and Biological Rhythms. 2017. 39-48.

19. Kamen G, Gabriel D, et al. Essentials of electromyography. Human Kinetics; 2010. Available at https:// uk.humankinetics.com/products/essentials-of-electromyography-ebook, accessed on 1st August 2018.

20. Cartwright RD, Wood E, et al. Adjustment disorders of sleep: The sleep effects of a major stressful event and its resolution. Psychiatry Res 1991 Dec;39(3):199-209.

21. Lohitashwa R, Kadli N, Kisan R, Sindhuja A, Deshpande D, et al. Effect of stress on sleep quality in young adult medical students : a cross sectional study. Int J Res Med Sci (Internet). 2015;3(12): 3519-23. Available from: www.msjonline.org.

22. Vranesh JG, Madrid G, Bautista J, Ching P, Hicks RA, et al. Time perspective and sleep problems. Percept Mot Skills. 1999;88(1):23-4.

23. Lack LC, et al. Delayed sleep and sleep loss in university students. J Am Coll Health 1986 Nov;35(3):105-10.

24. Soper B, Kelly WE, et al. A preliminary study of sleep length and hallucinations in a college student population. Coll Stud J. 1997;31(2):272-5.

25. Gilbert SP, Weaver CC. Sleep quality and academic performance in university students: A wake-up call for college psychologists. J College Stud Psychother. 2010;24(4):295-306.

26. van der Heijden KB, Vermeulen MCM, Donjacour CEHM, Gordijn MCM, Hamburger HL, Meijer AM, et al. Chronic sleep reduction is associated with academic achievement and study concentration in higher education students. J Sleep Res 2018 Apr;27(2):165-74.

27. Orzech KM, Salafsky DB, Hamilton LA, et al. The state of sleep among college students at a large public University. J Am Coll Heal. 2011;59(7):612-9.

28. Åkerstedt T, Philip P, Capelli A, Kecklund G, et al. Sleep loss and accidents-Work hours, life style, and sleep pathology. Progress in brain research 2011;190:169-88.

29. Shochat $\mathrm{T}$, et al. Impact of lifestyle and technology developments on sleep. Nat Sci Sleep 2012;4:19-31.

30. Scott JPR, McNaughton LR, Polman RCJ. Effects of sleep deprivation and exercise on cognitive, motor performance and mood. Physiol Behav. 2006;87(2):396-408.

31. Léger D, Partinen M, Hirshkowitz M, Chokroverty S, Touchette E, Hedner J, et al. Daytime consequences of insomnia symptoms among outpatients in primary care practice: EQUINOX international survey. Sleep Med. 2010;11(10):999-1009.

32. Orzeł-Gryglewska J, et al. Consequences of sleep deprivation. Int J Occup Med Environ Health 2010;23(1):95-114.

33. Mullington JM, Haack $M$, Toth $M$, Serrador JM, Meier-Ewert $\mathrm{HK}$, et al. Cardiovascular, inflammatory, and metabolic consequences of sleep deprivation. Prog Cardiovasc Dis 2009;51(4):294-302.

34. Deng H-B, Tam T, Zee BC-Y, Chung RY-N, Su X, Jin L, et al. Short Sleep Duration Increases Metabolic Impact in Healthy Adults: A Population-Based Cohort Study. Sleep 2017 Oct 1;40(10).

35. Vandeputte $\mathrm{M}$, de Weerd A, et al. Sleep disorders and depressive feelings: a global survey with the Beck depression scale. Sleep Med 2003 Jul;4(4):343-5.

36. Kilic K, Karatas H, Dönmez-Demir B, Eren-Kocak E, Gursoy-Ozdemir Y, Can A, et al. Inadequate brain glycogen or sleep increases spreading depression susceptibility. Ann Neurol 2018 Jan;83(1):61-73. 
37. Lewis GJ, Bates TC, et al. Sex, Sleep Deprivation, and the Anxious Brain. Psychologist 2013 Apr;26(3):194-8.

38. Bonnet $\mathrm{MH}$, Arand DL, et al. Clinical effects of sleep fragmentation versus sleep deprivation. sleep Med Rev. 2003;7:297-310.

39. Beccuti G, Pannain S, et al. Sleep and obesity. Curr Opin Clin Nutr Metab Care 2011 Jul;14(4):402-12.

40. Taheri S, Lin L, Austin D, Young T, Mignot E, et al. Short sleep duration is associated with reduced leptin, elevated ghrelin, and increased body mass index. PLoS Med 2004 Dec;1(3):e62.

41. Hariharananda P. Kriya yoga: the scientific process of soul culture and the essence of all religions (Internet). Motilal Banarsidass Publishers; 2013 (cited 2017 Apr 22). 291.

42. Smits. The energy body in yoga - Ekhart Yoga . 2015 (cited 2017 Apr 22). Available from: https://www.ekhartyoga. com/blog/the-energy-body-in-yoga.

43. Rshikesan P, Subramanya P, Singh D, et al. Sleep quality and body composition variations in obese male adults after 14 weeks of yoga intervention: A randomized controlled trial. Int J Yoga2017;10(3):128.

44. Ebrahimi M, Guilan-Nejad TN, Pordanjani AF, et al. Effect of yoga and aerobics exercise on sleep quality in women with Type 2 diabetes: a randomized controlled trial. Sleep Sci 2017;10(2):68-72.

45. Halpern J, Cohen M, Kennedy G, Reece J, Cahan C, Baharav A, et al. Yoga for improving sleep quality and quality of life for older adults. Altern Ther Health Med 2014;20(3):37-46.

46. Rao M, Metri KG, Nagarathna $R$, Nagendra $H$, et al. Effects of Mind Sound Resonance Technique (Yogic Relaxation) on Psychological States, Sleep Quality, and Cognitive Functions in Female Teachers: A Randomized, Controlled Trial. Adv Mind Body Med 2017;31(1):4-9.

47. Buysse DJ, Reynolds CF, Monk TH, Berman SR, Kupfer DJ, et al. The Pittsburgh sleep quality index: A new instrument for psychiatric practice and research. psychiatry Res. 1989;28(2):193-213.

48. Cohen S, Kamarck T, Mermelstein R, et al. A Global Measure of Perceived Stress. J Health Soc Behav 1983;24(4):385-96.

49. World Health Organization. WHOQOL-BREF: introduction, administration, scoring and generic version of the assessment: field trial version, december 1996. Geneva; 1996.

50. Deshpande S, Nagendra HR, Raghuram N, et al. A randomized control trial of the effect of yoga on Gunas (personality) and Health in normal healthy volunteers. Int J Yoga 2008 Jan;1(1):2-10.

51. Patra S, Telles S, et al. Positive impact of cyclic meditation on subsequent sleep. Med Sci Monit 2009 Jul;15(7):CR375-81.

52. Hegde A, Metri K, Chwadhary P, Babu N, Nagendra HR, et al. Effects of yoga on cardiac health sleep quality, mental health and quality of life of elderly individuals with chronic ailments. Voice Res. 2017;6(1):1-5. 